Western University

Scholarship@Western

Human Environments Analysis Lab (HEAL)

$1-2020$

Food for thought: Comparing self-reported versus curbside measurements of household food wasting behavior and the predictive capacity of behavioral determinants

Paul van der Werf

Jamie A. Seabrook

Jason A. Gilliland 


\title{
Food for thought: Comparing self-reported versus curbside measurements of household food wasting behavior and the predictive capacity of behavioral determinants
}

\author{
Paul van der Werf ${ }^{\mathrm{a}, \mathrm{b}, *}$, Jamie A. Seabrook ${ }^{\mathrm{a}, \mathrm{c}, \mathrm{d}, \mathrm{e}, \mathrm{f,g}}$, Jason A. Gilliland ${ }^{\mathrm{a}, \mathrm{b}, \mathrm{c}, \mathrm{d}, \mathrm{e}, \mathrm{h}}$ \\ ${ }^{a}$ Human Environments Analysis Laboratory, University of Western Ontario, London, ON, Canada \\ ${ }^{\mathrm{b}}$ Department of Geography, University of Western Ontario, London, ON, Canada \\ ${ }^{\mathrm{c}}$ Department of Paediatrics, University of Western Ontario, London, ON, Canada \\ ${ }^{\mathrm{d}}$ Lawson Health Research Institute, London, ON, Canada \\ e Children's Health Research Institute, London, ON, Canada \\ ${ }^{\mathrm{f}}$ School of Food and Nutritional Sciences, Brescia University College, University of Western Ontario, London, ON, Canada \\ ${ }^{\mathrm{g}}$ Department of Epidemiology E Biostatistics, University of Western Ontario, London, ON, Canada \\ ${ }^{\mathrm{h}}$ School of Health Studies, University of Western Ontario, London, ON, Canada
}

\section{A R T I C L E I N F O}

\section{Article history:}

Received 12 January 2019

Revised 28 July 2019

Accepted 23 September 2019

Available online 3 October 2019

\section{Keywords:}

Household food waste

Theory of planned behavior

Survey

Self-reported behavior

Direct measurement

\begin{abstract}
A B S T R A C T
A survey, based on an expanded Theory of Planned Behavior (TPB), was used to indirectly measure self-reported food wasting and its behavioral determinants. This was complemented with directly and objectively measured food waste in curbside garbage samples. Households $(\mathrm{n}=189)$ reported throwing out avoidable food waste a mean of 5.48 times $(S D=5.58)$ and 6.63 portions $(S D=6.61)$ the week prior to completing the survey. These same households threw out a mean of 2,783 $\mathrm{g} /$ week of food waste $(\mathrm{SD}=2,664)$ in a curbside garbage sample, with $63.27 \%$ of this consisting of avoidable food waste There were weak to fair correlations between self-reported and curbside food waste samples. The direction and level of significance of all correlations of TPB behavioral determinants with self-reported and curbside food waste samples were similar, although the correlation coefficients were higher for selfreported food wasting. A linear regression $\left(R^{2}=0.34, p<0.001\right)$ on self-reported avoidable food waste frequency demonstrated that it was significantly $(\mathrm{p}<0.05)$ associated with perceived behavioral control, personal attitude, number of people per household, gender and employment status. This was contrasted with a linear regression $\left(R^{2}=0.19, p<0.001\right)$ on curbside avoidable food waste which was also significantly $(\mathrm{p}<0.05)$ associated with perceived behavioral control and number of people per household, but also housing tenure type (owner-occupancy vs tenancy) and the good provider identity. In general, self-reported results should be used with caution as they may underestimate food waste disposal and consideration should be given to supplement, if not replace, them with direct measurement of food waste disposal.
\end{abstract}

(c) 2019 Elsevier Ltd. All rights reserved.

\section{Introduction}

World food production and per capita calorie intake has increased substantially in the past century (Nellemann et al., 2009). Total production of food has been estimated at $900 \mathrm{~kg} / \mathrm{cap}-$ ita/year in North America and Europe (Gustavsson et al., 2011), while annual per capita food consumption estimates range from 500 to $1,006 \mathrm{~kg}$ (Alexandratos and Bruinsma, 2012; Beretta et al.,

* Corresponding author at: Department of Geography, Social Sciences Building, Room 2333 University of Western Ontario, 1151 Richmond St, London, ON N6A 3K7, Canada.

E-mail address: pvande2@uwo.ca (P. van der Werf).
2013; Kantor et al., 1997; Tike, 2010; Viinisalo et al., 2008). A recent systematic review of food waste in developed countries (e.g. Canada, United Kingdom, United States) estimated that a mean of $114.3 \mathrm{~kg} /$ capita/year $(\mathrm{SD}=68.7)$ of food is wasted by households (van der Werf and Gilliland, 2017), with a broad range of estimates from $18.8 \mathrm{~kg} /$ capita/year (Lebersorger and Schneider, 2011 ) to $396 \mathrm{~kg} /$ capita/year (CEC, 2017). The large variability in these estimates is a result of geographic differences, the scale of measurement (e.g., global, regional, city, household), the method used to collect food waste data (e.g., direct collection through waste composition studies versus indirect collection through diary studies and surveys), and whether the estimate includes avoidable and/or unavoidable food waste. Avoidable food waste consists of 
food that was at one-point edible, while unavoidable food waste is food that is not normally edible (e.g., banana peel) (WRAP, 2009). The present study compares indirect and direct measurements by assessing the differences between household avoidable food waste disposal in the garbage stream measured (1) indirectly, via a selfreport survey, and (2) directly, through the collection, sorting, and weighing of curbside food waste samples from the same surveyed households.

\subsection{Food waste measurement issues}

There is some agreement among researchers that further research is required to improve the measurement of food waste, because to date it has been measured using a variety of direct and indirect methods which have yielded largely incomparable results (Langley et al., 2009; Parfitt et al., 2010; Porpino, 2016; van der Werf and Gilliland, 2017). More accurate and precise food waste estimates can be used to inform and ultimately evaluate the impact of food waste reduction policies and interventions.

Estimates of food waste can be made at jurisdictional (e.g., country) or generator (e.g., household) levels. To make jurisdictional scale estimates food waste can be measured using indirect (Kreith and Tchobanoglous, 2002; Sharma and McBean, 2007) or direct methods (ASTM, 2008; Klee and Carruth, 1970; Sharma and McBean, 2007). Most studies have focussed on using an indirect approach to collect global and regional (Gustavsson et al., 2011) and country-wide food waste estimates (Buzby and Hyman, 2012), although in some cases a combination of direct (e.g., collection of waste samples) and indirect (e.g., diary studies) (WRAP, 2009, 2013) methods have been used to develop country wide estimates.

Similarly, indirect and direct food waste measurement methods can also be used to develop estimates for generators (e.g., households). This is often measured indirectly by self-reporting food waste quantities through diaries or surveys (Jorissen et al., 2015; Koivupuro et al., 2012), but in some cases it has been measured directly through collection of waste samples (Parizeau et al., 2015; Silvennoinen et al., 2014).

A key issue with indirect measurements is that estimates are made without the benefit of scientifically measuring actual food waste. For jurisdictional estimates quantities of food are put into product categories and then waste is imputed through the use of waste factors (i.e., \% of a product category assumed to become waste). For generator estimates quantities of food are estimated by a member of a household. A number of researchers recommend that direct measurement involving the collection, manual sorting, weighing, and statistical analysis of samples collected at the point of disposal be used for quantifying waste (Maystre and Viret, 1995; Rugg, 1997) and specifically for food waste (Abdulla et al., 2013; van der Werf and Gilliland, 2017).

\subsection{Vulnerability of self-reported data}

The value of self-reported data has been questioned in several studies of different subject matter (Dhurandhar et al., 2015; Handal et al., 2015; Prince et al., 2008). In a study on food intake, Whybrow et al. (2016) found that self-reported underestimation was pervasive but difficult to identify because the estimates provided were within plausible ranges. Further, they suggest that people are inconsistent self-reporters of food intake data depending where this measurement is taking place (e.g., in a laboratory or at home). In a systematic review comparing self-reported measures and direct measures of pro-environmental behavior, Kormos and Gifford (2014) advised researchers to be cautious about self-reported data, as they may lead to misleading conclusions. Specific to waste management, Chung (2008) investigated the accuracy of self-reported plastic bag disposal in comparison to direct measurement in Hong Kong and reported that selfreported estimates were only about one-fifth of the estimate obtained from direct measurement. This differs from Yu and Maclaren (1995) who reported that estimates of total institutional, commercial, and industrial waste from self-reported surveys were relatively accurate when compared to direct measurement, but not for waste composition.

Surveys are often used to gather information on household food waste generation and its behavioral determinants. This is because surveys are relatively inexpensive and it can be more challenging to collect household food waste samples. However, van Herpen et al. (2016, pp. 2, 3) reported that surveys of food waste resulted in low levels of reported food waste and are "less appropriate for measuring food waste" in comparison to other methods. It results in an underestimation of actual behavior and is not recommended for estimating food waste. Visschers et al. (2016) had participants estimate how many handfuls of various food types were wasted in a week. This amounts to asking people to estimate the volume of food they and other family members generated. Visschers et al. (2016, p. 76) recognized this weakness and concluded that "future research should aim to validate our self-report measure with more objective estimates of household food waste, for example by the collection of waste." Russell et al. (2017) also argue that future research should examine the relationship between self-reported and observational food waste measurement.

\subsection{Using an expanded theory of planned behavior to measure household food waste}

A growing number of researchers have highlighted the need to better understand why households waste food (Melbye et al., 2016; Neff, 2015; Romani et al., 2018). Schanes et al. (2018) reported that our understanding of household food wasting behaviors is incomplete and that current prevailing approaches to better understand these behaviors include social practice theory and psychology-related approaches (i.e., behavioral models).

Looking through the lens of social practice theory, Evans (2011) puts forward that household food waste "cannot be conceptualized as a problem of individual consumer behavior" or blamed on a "throwaway society" (p. 429) or other moralizing (Evans, 2012). Ganglbauer et al. (2013) suggest that choices about food and waste are impacted more by the multifaceted decision-making environment, in which household food management takes place, rather than people's attitudes or motivation. This includes the pressure to eat properly (including buying more fresh food), the mismatch between food provisioning and consumption, and between rhythms of everyday life and the temporalities of food (Evans, 2011, 2012; Evans, 2014). This is reinforced by Lee (2018) who reported that how often and the type of retailer where food is purchased can contribute to over-purchase and subsequently food waste. Further, Cappellini and Parsons (2012) suggested that eating leftovers is driven more by practices of sacrifice and thrift than reducing food waste. That said, Evans et al. (2017) highlights that food waste prevention starts with personal responsibility of individual consumers and when seen by food retailers leads to more responsible behavior on their part. This is an inflection point where behavioral models can be used to try and isolate and measure individual household food wasting behaviors and the approach we used in our research.

The Theory of Planned Behavior (TPB) (Ajzen, 1991), for instance, is proving to be an effective conceptual framework for examining food wasting behaviors. The TPB was designed to "predict and explain human behavior in specific contexts" (Ajzen, 1991, p. 181) and posits that, if volitional, as is the case with food wasting behavior, "people's intentions and behaviors follow reasonably and 
consistently from their beliefs no matter how these beliefs were formed" (Ajzen, 2015, p. 127). Researchers that have expanded this framework to include determinants related to household food management, have used surveys to measure behavioral antecedents, such as intention to not waste food, as well as selfreported food wasting behavior (Graham-Rowe et al., 2015; Stancu et al., 2016; Stefan et al., 2013; Visschers et al., 2016).

To date, this model appears to be more effective at measuring food wasting intention than actual behavior and this may in part be due to a value-action gap as described by Barr (2006). For instance, Stefan et al. (2013), in a survey of Romanian consumers, reported that moral attitude had a significant positive impact and lack of concern a significant negative impact on the intention to waste food, although intention to not waste food did not have a significant effect on food waste behavior, with the variance being better explained by planning and especially shopping routines. Graham-Rowe et al. (2015), in surveys of United Kingdom households, found that using an extended TPB explained more than $60 \%$ of the variance in intention to reduce fruit and vegetable waste, with attitude, subjective norm, perceived behavioral control, self-identity and anticipated regret emerging as significant linear predictors. However, the amount of variance in behavior accounted for by the TPB model was relatively small (5\%). Stancu et al. (2016), in a survey of Danish households, reported that perceived behavioral control and routines related to shopping and leftover reuse were the main drivers of food waste. Thus, to date the TPB appears to be a better predictor of food wasting intention than behavior.

While the TPB suggests that intention is the main antecedent of behavior, it does allow that perceived behavioral control may also influence behavior (Azjen, 1991). This influence is represented by the dotted line leading from perceived behavioral control to behavior in Fig. 1. Findings based on linear regression analyses of data from a recent survey of 1,263 households in London, Ontario, Canada indicated that self-reported food wasting behavior was more strongly influenced by perceived behavioral control than intention (van der Werf et al., 2019). This may be because while people do not intend to throw out food they clearly do, and perceived behavioral control may function as a proxy for behavioural efficacy. These results suggest that perceived behavioral control may have a greater relationship with food wasting behavior than intention and may potentially be a better starting point for intervention development.

All of the above noted studies rely on self-reported food wasting behavior. While it would seem reasonably easy for a survey respondent to assess their individual intention to not waste food, using an indirect measurement method, that is, memory, to estimate and self-report their household's food wasting behavior is clearly more susceptible to error, including recall and response bias. It does not measure actual behavior. Researchers such as (van der Werf and Gilliland, 2017; Visschers et al., 2016) have recommended the direct measurement of food waste to help better understand household food wasting behavior.

\subsection{The present study}

A household survey, using the TPB as its basis, was developed and disseminated to measure food wasting behavioral determinants and self-reported food wasting behavior. The TPB model was expanded and replicated after Visschers et al. (2016), to include consideration of personal norms, the good provider identity, and household planning habits (Fig. 1). The good provider identity is essentially the need to have plenty of food on hand for various expected and unexpected situations (Evans, 2011; Graham-Rowe et al., 2014; Visschers et al., 2016). Household planning habits refers to the management of food purchases which may be a factor in the amount of food that becomes waste (Parizeau et al., 2015; Stefan et al., 2013). The survey was complemented with the collection of avoidable food waste samples from household garbage bins placed at the curbside.

This study had three objectives. (1) To measure the relationship between a household's self-reported and curbside avoidable food wasting behavior. (2) To examine differences in the relationships that self-reported and curbside avoidable food wasting behavior have with the behavioral determinants of an expanded TPB model. (3) To identify the influence of intention and perceived behavioral control on a household's self-reported and curbside avoidable food wasting behavior. We include two hypotheses: (1) Self-reported food waste will be positively correlated to curbside food waste disposal; and (2) Both self-reported and curbside behavior will be

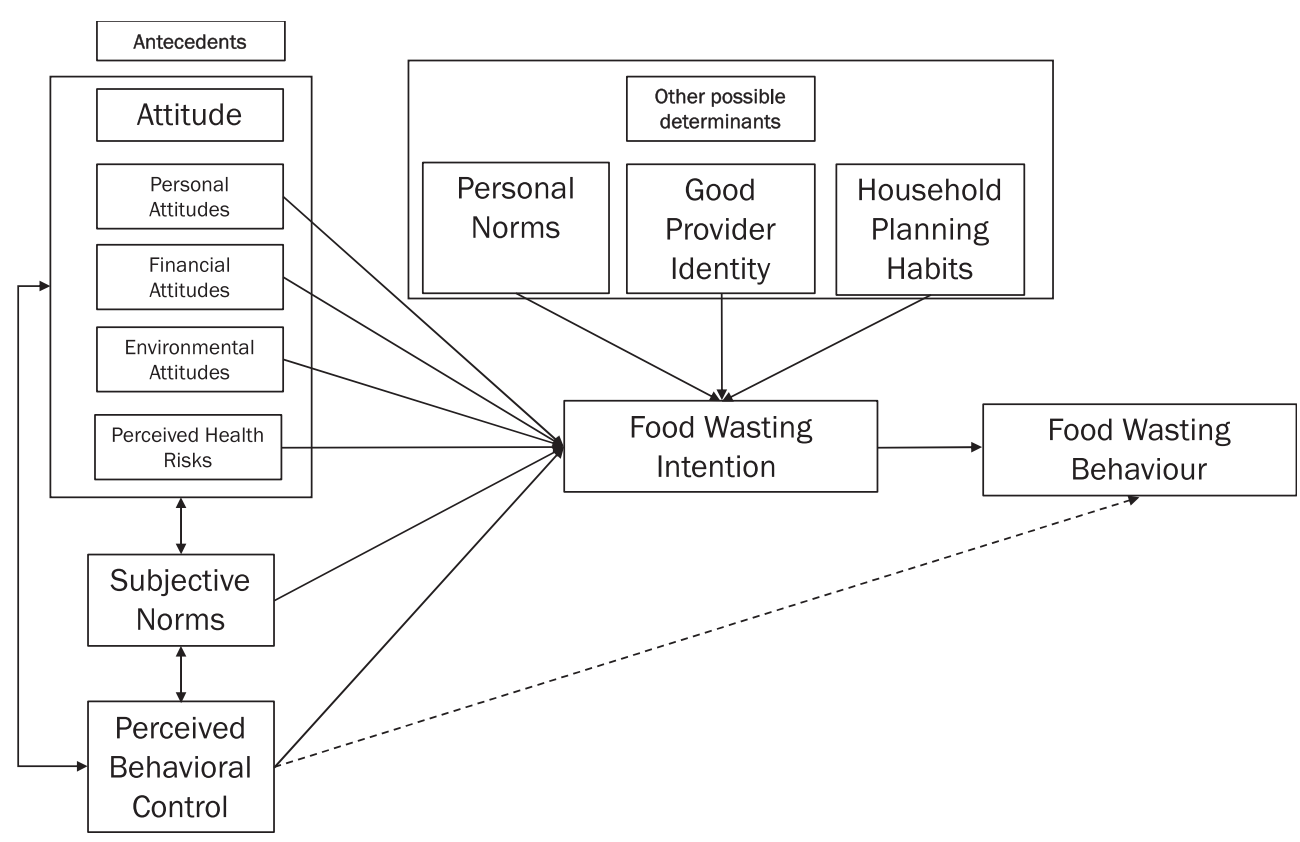

Fig. 1. Theory of planned behavior and other possible determinants model (Ajzen, 1991; Visschers et al., 2016). 
more strongly correlated to perceived behavioral control than intention to avoid food waste.

\section{Materials and methods}

Research was undertaken on single-family households in London, Ontario, Canada (City) (population 390,000). The City collects single family curbside garbage and recyclables every six business days (i.e., waste collection day changes each week). Waste collection, disposal, and diversion are undertaken by a combination of municipal and contracted private-sector forces. There is currently no curbside program to separately remove source separated food wastes, although approximately 60,000 backyard composters have been distributed throughout the City in the last 25 years and the City is currently working toward the implementation of a "green bin” program (J. Stanford, personal communication, 15 May 2017).

\subsection{Survey design}

Using TPB as a conceptual framework (Ajzen, 2006a, 2006b), and questions from previously validated and well-used household/consumer food waste surveys, including Visschers et al. (2016), Stancu et al. (2016) and WRAP (2007), we developed and delivered a 71 question on-line Household Food Waste Survey.

The introduction to this survey was used to collect socio-demographic information (e.g., age, household income) and respondent responsibility as it related to food shopping and food preparation (adapted from WRAP (2007)), as well as taking out waste and recycling on waste collection day. A question on backyard composter usage frequency was used as a surrogate for pro-environmental behavior.

Using an approach similar to Visschers et al. (2016), respondents were asked to self-report the estimated frequency and portions (i.e., handfuls) of edible (i.e., avoidable) food waste thrown out, for any reason, over the past week by six food types (i.e., bread and baked goods, meat and fish, dairy, fruit and vegetables, dried food and other food). Respondents could select from 8 options (i.e., 0, 1, 2, 3, 4, 5, 6, 7+ times per week). The household food wasting frequency and portions were individually summed to provide household food waste estimates.

The remainder of the survey used the expanded TPB model to ask questions about food wasting intentions, intention's antecedents including attitudes (personal attitudes, financial attitudes, environmental attitudes, perceived health risk), subjective norms and perceived behavioral control, as well as non-TPB food wasting determinants (personal norms, good provider identity and household planning habits) (Fig. 1). Questions about food wasting intentions, its antecedents and other possible determinants, except for environmental attitudes, were directly adapted from (Visschers et al., 2016, p. 77). A 7-point Likert scale was used, with higher scores representing greater agreement with a given question. A final question asked survey respondents if they would volunteer their household for further study. This included the collection of curbside garbage samples on a household volunteer's waste collection day, and manually sorting and weighing the various food waste fractions in these samples.

\subsection{Survey dissemination and sample}

Between May and July 2017, an online version of the household food waste survey was made available for completion. An opportunistic survey approach and attendant comprehensive survey dissemination strategy was deployed to inform the entire city about this survey and encourage city-wide responses. Various efforts were made to disseminate information about the survey as widely as possible, by the authors and City staff. A print and digital flyer was created and served as the key vehicle to present uniform information to potential respondents. It directed respondents to a website where they could complete the survey. An extensive social media campaign was launched that included sustained dissemination via the City's and authors' various social media platforms including Facebook, Twitter and Instagram. A terrestrial media campaign included both print and radio advertisements. Email contact was made to the chairpersons of all community association groups $(n=25)$ with a request to distribute survey information to their members via email or their social media platforms. Approximately 500 flyers were distributed at various festivals and events. Survey responses were tracked and mapped, across the city, on a weekly basis, to identify underrepresented areas across the city. This resulted in the hand delivery of approximately 1,000 flyers. It took survey respondents $10-15 \mathrm{~min}$ to complete the survey.

\subsection{Curbside garbage sample collection and sorting avoidable food waste}

From the entire sample of survey respondents $(n=1,629)$, a subgroup of 418 single-family households who met inclusion criteria (i.e., adult living in a dwelling within the city with curbside pickup) indicated on the survey that they would volunteer to participate further in this study, including having their curbside garbage collected and examined. Volunteer household locations were mapped and delineated by the City's six waste collection zones (collection in these zones occurs on consecutive weekdays). Due to resource limitations, a decision was made to select approximately half of these households for further study. A key logistical challenge was to ensure that the study team could collect curbside garbage samples prior to the arrival of the City waste collection vehicle, and this informed household selection. Using the map, 218 volunteer households, consisting of 29-49 households per waste collection zone, were identified by the researchers for further study. The focus was on identifying clusters of households (i.e., households in close proximity to each other) to facilitate rapid sample collection.

Household volunteer curbside garbage samples (i.e., all garbage set out by each household) were collected once between 18 and 25 September 2017 and labelled with a unique code. This time was deliberately selected to account for seasonality (i.e., avoid summer when more fruits and vegetables are consumed) and similar waste generation (i.e., both the survey and curbside samples were collected when children were in school and avoided summer holidays). Households were not alerted prior to the collection of these samples. A total of 189 curbside garbage samples were successfully collected, with 29 samples missed because these households either had not set out garbage that day or because City crews collected the sample prior to the research sampling crew arrival. Samples were taken to an indoor sorting location and individually weighed. The avoidable and unavoidable food waste in each sample was manually extracted and weighed by the six above-noted food types; however, this study focuses on avoidable food waste.

\subsection{Statistical analysis}

Survey and curbside garbage sample data were linked by household address and data aggregated to ensure volunteer anonymity. Data were analyzed using IBM SPSS Statistics version 25 (Armonk, New York, United States). Categorical variables were summarized as percentages, and continuous outcomes presented as mean \pm standard deviation (SD) or median, where appropriate. Mean scores were developed per behavioral determinant (i.e., psychological construct). Cronbach's alpha was used to measure the 
internal reliability of the scales used to assess the behavioral determinants of intention, attitudes, subjective norms, perceived behavioral control, personal norms, good provider identity and household planning habits. If the internal reliability was greater than 0.6 (i.e., reasonable) (Nunnally and Bernstein, 1978), it was used in subsequent analyses. On that basis, environmental attitudes ( $\alpha=0.49$ ) was excluded from further analysis (See Appendix, Table A.1).

The Spearman rank correlation coefficient was used to assess the bivariate strength and direction of the association between self-reported and curbside avoidable food wasting, and between expanded TPB behavioral determinants and avoidable food wasting behavior. Correlation coefficients were interpreted as follows: $\geq 0.75$ very good to excellent; $0.50-0.75$ moderate to good; 0.25 0.49 fair; and $\leq 0.25$ little to no correlation (Colton, 1974). Multiple linear regression models were developed to assess the relative effects of various predictors on intention to avoid food waste, perceived behavioral control, and self-reported and curbside avoidable food wasting behavior. Predictor variables that had a statistically significant bivariate relationship $(p<0.05)$ with selfreported food wasting frequency and curbside avoidable food waste were included in the multiple regression analyses. As part of the analysis, we obtained collinearity diagnostics (i.e., Tolerance statistic, Variance inflation factor, Condition index) to assess multicollinearity. A 2-sided $\mathrm{p}$ value $<0.05$ was considered statistically significant.

\section{Results}

\subsection{Socio-demographic profile of volunteer households}

The socio-demographic profile of the $n=189$ survey respondents/household volunteers is presented in Table 1 . Respondents were typically female, with few children and employed. They included more women and more 35-64 year olds than the London census metropolitan area average (Statistics Canada, 2016). Further, respondent households included more 3-5 person and fewer one-person households; and more households with greater than $\$ 60,000$, incomes when compared to census data (Statistics Canada, 2016).

\subsection{Comparison of self-reported and curbside avoidable food waste}

As depicted in Table 2, households $(n=189)$ reported that they threw out avoidable food waste a mean of 5.48 times $(\mathrm{SD}=5.58)$ and 6.63 portions ( $S D=6.61$ ) in the week prior to completing the survey. These same households threw out a mean of $2,783 \mathrm{~g} /$ week of total food waste $(S D=2,664)$ in a curbside garbage sample, with $63.27 \%$ (i.e., $1,760 \mathrm{~g} /$ week) of this consisting of avoidable food waste. Fruit and vegetables, and then bread and baked goods, comprised the highest proportions of avoidable food waste. For fruit and vegetables, this was considerably higher in curbside samples, where it comprised $51.82 \%$ of avoidable food waste (Table 2).

Approximately $10.02 \%$ households self-reported throwing out no food waste over the past week. The mean avoidable food waste in their curbside sample was $830 \mathrm{~g}$ ( $\mathrm{SD}=1,460$ ). This is contrasted with $4.76 \%$ of households that threw out no avoidable food waste in their curbside sample. The mean self-reported weekly food wasting frequency for these households was 2.33 times ( $S D=2.65$ ).

There were a number of significant bivariate Spearman rank correlations. This included excellent, positive and significant $(p=0.01)$ correlations between self-reported avoidable food wasting frequency and portions, for total food waste $(r=0.88)$, and by food type ( $r=0.81-0.88$ ). Secondly, there were fair, positive and significant correlations between curbside and self-reported bread and baked goods and total avoidable food waste (Table 3). The amount of avoidable curbside food waste was good and significantly correlated with the total curbside garbage weight $(r=0.62$,

Table 1

Socio-demographic profile (\%) of survey respondents $(S)(n=189)$ and population $(P)$.

\begin{tabular}{|c|c|c|c|c|c|c|c|c|c|c|}
\hline Gender & $\mathrm{S}$ & $\mathrm{P}$ & People in household & $\mathrm{S}$ & $\mathrm{P}$ & Household income & $\mathrm{S}$ & $\mathrm{P}$ & Housing tenure & $\mathrm{S}$ \\
\hline Female & 79.89 & 51.50 & 1 & 8.50 & 30.15 & $<40,000$ & 15.51 & 29.02 & Live Rent Free & 2.66 \\
\hline Male & 19.58 & 48.50 & 2 & 34.60 & 34.77 & $\$ 40-60,000$ & 14.44 & 17.34 & Pay Rent & 9.57 \\
\hline \multirow[t]{4}{*}{ Other } & 0.53 & & 3 & 20.20 & 14.83 & $\$ 60-80,000$ & 19.79 & 14.04 & Pay Mortgage & 61.17 \\
\hline & & & 4 & 21.80 & 13.09 & $\$ 80-\$ 100,000$ & 19.79 & 11.17 & Own Home Outright & 25.00 \\
\hline & & & 5 & 11.70 & 7.16 & $>\$ 100,000$ & 30.48 & 28.44 & Other & 1.60 \\
\hline & & & $6+$ & 3.20 & & & & & & \\
\hline Age & $\mathbf{S}$ & $\mathbf{P}$ & Children in Household & $\mathbf{S}$ & $\mathbf{P}$ & Employment Status & $\mathbf{S}$ & & & \\
\hline $18-24$ & 3.70 & 9.46 & 0 & 54.55 & & Unemployed & 3.19 & & & \\
\hline $25-34$ & 15.30 & 17.11 & 1 & 17.11 & & Student & 3.72 & & & \\
\hline $35-44$ & 27.50 & 15.76 & 2 & 17.65 & & Stay at home parent & 3.72 & & & \\
\hline $45-54$ & 20.60 & 18.20 & 3 & 8.56 & & Work part time & 18.09 & & & \\
\hline $55-64$ & 23.30 & 17.47 & 4 & 1.60 & & Work full time & 52.66 & & & \\
\hline $65+$ & 9.50 & 22.00 & $5+$ & 0.53 & & Retired & 18.62 & & & \\
\hline
\end{tabular}

Table 2

Average self-reported and curbside avoidable food waste.

\begin{tabular}{|c|c|c|c|c|c|c|c|c|c|c|c|c|}
\hline & \multicolumn{7}{|c|}{ Self-reported } & \multicolumn{5}{|c|}{ Curbside } \\
\hline & \multicolumn{3}{|c|}{ Frequency/week } & \multicolumn{4}{|c|}{ Portions/week } & \multicolumn{5}{|c|}{ Grams/week } \\
\hline & M & SD & Mdn & $\%$ & M & SD & Mdn & $\%$ & M & SD & Mdn & $\%$ \\
\hline Bread and baked goods & 0.93 & 1.24 & 1.00 & 16.97 & 1.50 & 1.94 & 1.00 & 22.62 & 354 & 483 & 172 & 20.09 \\
\hline Meat and fish & 0.75 & 1.20 & 0.00 & 13.69 & 0.93 & 1.40 & 0.00 & 14.03 & 131 & 253 & - & 7.44 \\
\hline Dairy (e.g. milk, cheese and yoghurt) & 0.52 & 0.84 & 0.00 & 9.49 & 0.66 & 1.09 & 0.00 & 9.95 & 50 & 134 & - & 2.85 \\
\hline Fruit and vegetables & 1.79 & 1.76 & 1.00 & 32.66 & 2.13 & 2.11 & 2.00 & 32.13 & 912 & 1,209 & 462 & 51.82 \\
\hline Dried food (e.g. cereal) & 0.45 & 1.06 & 0.00 & 8.21 & 0.40 & 0.83 & 0.00 & 6.03 & 207 & 436 & 20 & 11.78 \\
\hline Other food & 1.04 & 1.38 & 1.00 & 18.98 & 1.01 & 1.38 & 0.00 & 15.23 & 106 & 263 & - & 6.02 \\
\hline Total & 5.48 & 5.58 & 4.00 & 100.00 & 6.63 & 6.61 & 5.00 & 100.00 & 1,760 & 1,914 & 1,132 & 100.00 \\
\hline
\end{tabular}


Table 3

Spearman rank correlations between curbside collection and self-reported frequency and portions of food waste.

\begin{tabular}{lll}
\hline Food type & Frequency & Portions \\
\hline Bread and baked goods & $0.33^{* * *}$ & $0.40^{* *}$ \\
Meat and fish & $0.21^{* *}$ & $0.27^{* *}$ \\
Dairy & 0.11 & 0.09 \\
Fruit and vegetables & $0.26^{* *}$ & $0.25^{* *}$ \\
Dried food & $0.20^{* * *}$ & $0.19^{*}$ \\
Other food & $0.15^{* *}$ & $0.22^{* * *}$ \\
Total & $0.36^{* * *}$ & $0.40^{* * *}$ \\
\hline
\end{tabular}

* Correlation is significant at the 0.05 level (2-tailed).

** Correlation is significant at the 0.01 level (2-tailed).

*** Correlation is significant at the 0.001 level (2-tailed).

$p=0.01$ ), suggesting that households that set out more garbage on their collection day set out more avoidable food waste.

\subsection{Comparison of self-reported and curbside avoidable food waste with behavioral determinants}

The direction and level of significance of Spearman rank correlations with behavioral determinants was similar for self-reported frequency and portions and curbside avoidable food waste, although the strength of these relationships was considerably weaker for curbside avoidable food waste (Table 4). Perceived behavioral control and intention were fairly to moderately and negatively correlated with self-reported behavior, with similar but weaker correlations with curbside behavior. Personal attitudes and personal norms were also weakly to fairly negatively correlated with self-reported and curbside behavior, while the good provider identity was weakly positively correlated. In general, curbside behavior was weakly to not at all correlated with the behavioral determinants.

Linear regression analyses were undertaken to further examine potential factors associated with self-reported and direct curbside measurements of food waste. Perceived behavioral control, attitude and gender were negatively and significantly related, while the number of people in a household and employment status were positively and significantly related to self-reported frequency of food wasting behavior, explaining a moderate amount of variance $\left(\mathrm{R}^{2}=0.34\right)$ (Table 5). A linear regression analysis of curbside food wasting behavior showed that the number of people in a household and the good provider identity were positively and significantly related, and housing status and perceived behavioral control negatively and significantly related to curbside food wasting $\left(R^{2}=0.19\right)$ (Table 6$)$. Those that own their home outright

Table 4

Spearman rank correlations between self-reported and curbside food waste behavior with behavioral determinants related to food waste.

\begin{tabular}{|c|c|c|c|}
\hline \multirow[t]{2}{*}{ Behavioral determinants } & \multicolumn{2}{|c|}{$\begin{array}{l}\text { Self-reported } \\
\text { behavior }\end{array}$} & \multirow{2}{*}{$\begin{array}{l}\text { Curbside Behavior } \\
\text { Avoidable food } \\
\text { weight }\end{array}$} \\
\hline & Frequency & Portions & \\
\hline Intention to avoid food waste & $-0.43^{* *}$ & $-0.47^{* * *}$ & $-0.20^{* *}$ \\
\hline Personal attitudes & $-0.38^{* *}$ & $-0.39^{* *}$ & $-0.17^{* *}$ \\
\hline Financial attitudes & -0.05 & -0.09 & 0.10 \\
\hline Perceived health risks & $0.29^{* *}$ & $0.24^{* *}$ & $0.19^{* *}$ \\
\hline Perceived behavioral control & $-0.56^{* *}$ & $-0.57^{* * *}$ & $-0.28^{* *}$ \\
\hline Subjective norms & $-0.25^{* *}$ & $-0.25^{* *}$ & $-0.14^{* *}$ \\
\hline Personal norms & $-0.29^{* *}$ & $-0.34^{* *}$ & $-0.18^{* *}$ \\
\hline Good provider identity & $0.24^{* *}$ & $0.33^{* *}$ & $0.26^{* *}$ \\
\hline Household planning habits & -0.16 & $-0.20^{* *}$ & -0.01 \\
\hline
\end{tabular}

Table 5

Linear regression analysis on self-reported food wasting frequency.

\begin{tabular}{llll}
\hline & $\mathrm{B}$ & $\mathrm{SE}$ & $\beta$ \\
\hline (Constant) & 18.03 & 3.37 & \\
Gender & -1.92 & 0.92 & $-0.14^{* *}$ \\
Number in household & 1.02 & 0.28 & $0.23^{* * *}$ \\
Employment status & 0.68 & 0.32 & $0.14^{*}$ \\
Food shopping responsibility & -0.69 & 0.40 & -0.11 \\
Personal attitude & -0.45 & 0.10 & $-0.30^{* * *}$ \\
Perceived behavioral control & -0.25 & 0.05 & $-0.31^{* * *}$ \\
$\mathrm{R}^{2}=0.34, \mathrm{~F}(6,179)=17.09, \mathrm{p}<0.001$ & & & \\
\hline${ }^{*} \mathrm{p}<0.05$. & & & \\
${ }^{* * * *} \mathrm{p}<0.01$. & & & \\
$\mathrm{p}<0.001$. & & & \\
& & &
\end{tabular}

Table 6

Linear regression analysis on curbside avoidable food waste.

\begin{tabular}{llll}
\hline & $\mathrm{B}$ & $\mathrm{SE}$ & $\beta$ \\
\hline (Constant) & 3115.68 & 1394.835 & \\
Housing status & -702.78 & 232.762 & $-0.21^{* *}$ \\
Number in household & 438.99 & 205.567 & $0.24^{*}$ \\
Number of children in household & -411.89 & 238.446 & -0.20 \\
Backyard composter usage & -192.28 & 101.578 & -0.13 \\
Perceived behavioral control & -63.81 & 27.517 & $-0.19^{*}$ \\
Good provider identity & 88.54 & 29.939 & $0.22^{* *}$ \\
Household planning habits & 57.50 & 31.593 & 0.13 \\
$\mathrm{R}^{2}=0.19, \mathrm{~F}(7,174)=6.925, \mathrm{p}<0.001$ & & & \\
\hline$* \mathrm{p}<0.05$. & & & \\
$\mathrm{*}<0.01$. & & & \\
$\mathrm{p}<0.001$. & & &
\end{tabular}

Table 7

Linear regression analysis on perceived behavioral control.

\begin{tabular}{llll}
\hline & $\mathrm{B}$ & $\mathrm{SE}$ & $\beta$ \\
\hline (Constant) & 17.93 & 3.80 & \\
Number of children & -1.33 & 0.37 & $-0.22^{* * *}$ \\
Shopping responsibility & 0.76 & 0.44 & 0.10 \\
Intention & 0.23 & 0.08 & $0.17^{* *}$ \\
Personal attitudes & 0.29 & 0.12 & $0.16^{*}$ \\
Subjective norms & 0.43 & 0.13 & $0.20^{* * *}$ \\
Good provider identity & -0.32 & 0.07 & $-0.26^{* * *}$ \\
Household planning habits & 0.18 & 0.08 & $0.14^{*}$ \\
$\mathrm{R}^{2}=0.39, \mathrm{~F}(7,174)=17.431,<0.001$ & & & \\
\hline${ }^{*} \mathrm{p}<0.05$. & & & \\
${ }^{* * *} \mathrm{p}<0.01$. & & & \\
$\mathrm{p}<0.001$. & & &
\end{tabular}

appear to throw out significantly less $(p=0.01)$ than those who have a mortgage.

Perceived behavioral control and personal attitudes had a positive and significant relationship with the intention to avoid waste $\left(R^{2}=0.19\right)$ (Appendix Table A.2). However, the good provider identity and number of children had significant negative relationships, while subjective norms, intention, personal attitudes and household planning habits had significant positive relationships on perceived behavioral control, explaining a moderate amount of variance $\left(R^{2}=0.39\right)$ (Table 7$)$

\section{Discussion}

\subsection{Issues with self-reported food wasting}

Self-reported avoidable food wasting frequency and portions were both were positively correlated with avoidable curbside food waste; therefore, Hypothesis 1 was supported. The fair strength of 
the correlation, however, suggests an imperfect relationship between self-reported and curbside avoidable food wasting intensity and highlights the importance of collecting curbside waste samples to better understand actual behavior.

Seebauer et al. (2017) note that a household is not an individual and conversely an individual survey respondent may not be able to accurately assess household behavior. Asking a survey respondent to estimate the household frequency and portions (i.e., handfuls) of food wasting over the course of the previous week is challenging. They may be able to quantify their own behavior but struggle to sum the behavior of other family members.

Accurate estimation of portions is challenging and compounded by a respondent's ability to estimate volume. In a study of volume estimation of various beverage containers, Folkes and Matta (2004) reported that there are a number of factors, including container shape and contents, that may impair a subject's ability to accurately estimate their volume. For example, Ramstedt (2010) reported how self-reporting the volume of alcohol purchased was considerably lower than what was actually purchased, but better than self-reported alcohol consumption. This could be a result of poor volume estimating but also other factors such as observer bias.

Mindful of the time lag between survey completion and curbside waste sample collection, there appears to be a disconnection between self-reported food waste portions and curbside avoidable food waste. Survey respondents were asked to estimate how many handfuls of six food types were wasted over the previous week. While there does not appear to be an exact scientific volumetric equivalent for a handful, it is estimated to be between $1 / 4-1 / 2$ cup (i.e., 60-120 ml) (Hulin, 2011; Valigursky, 2011). FAO/Infoods (2012) shows that the density of solid food ranges from 0.2 to $1.2 \mathrm{~g} / \mathrm{ml}$. Using $90 \mathrm{ml}$ as a convenient handful volume the weight of self-reported food portions would range from 18 to $108 \mathrm{~g}$. Applying that to the mean of 6.63 portions of self-reported weekly food waste translates to $133-716 \mathrm{~g} /$ week of avoidable food wasted. This differs considerably from the mean $1,760 \mathrm{~g} /$ week of curbside avoidable food waste measured at these survey respondent's homes. While there are seasonal and other sources of variability that factor into amount of curbside food waste set out, the above noted portion estimates are quite low. Nevertheless, this finding is in line with other recent studies which argue that selfreported food wasting data underestimates the actual amount of food waste (Beretta et al., 2013; Jorissen et al., 2015; van Herpen et al., 2016). Further exacerbating this divergence is the limitation that curbside estimates of avoidable food wasting are underestimates of total food wasting because they do not encompass any food put down the drain, fed to pets, or put in the backyard composter. Given that correlations between indirect and direct estimates of food wasting are weak to fair it appears that survey respondents have some sense of the relative intensity of food wasting, but this does not translate well to absolute quantity of curbside food waste.

\subsection{Impact of how food waste is measured on the relationship with behavioral determinants}

As Ajzen (2011) notes, increased time between measuring intention and behavior can impact potential correlations because as time passes a person's attitudes, social norms and perceived behavioral control can change. The stronger bivariate correlations with self-reported behaviors (Table 4) could be a function of this phenomena as curbside samples were collected three-four months after the survey. However, one could argue that this time period is not particularly long and that the differences are related to their best estimate and/or desired assessment of their behaviors, rather than their actual behaviors. It could be further argued that the sur- vey had a therapeutic effect on respondents and that this impacted (i.e., reduced) their food wasting behavior. This effect would have been more likely if the curbside garbage sample had been collected in the weeks immediately after survey completion (and volunteering to participate in a future study). As noted, the time gap between survey completion and curbside garbage sample collection was deliberately selected to account for seasonality but had the ancillary benefit of reducing the likelihood of a therapeutic effect from the survey. Further and importantly we provided no advance notice about when a curbside sample was going to be collected.

The fact that essentially all self-reported and curbside behaviors are correlated with behavioral determinants in the same direction and with the same level of significance is an important finding which suggests that self-reported relationships carry at least partially through to curbside food wasting behaviors.

Survey respondents, as noted, were somewhat older and had higher incomes when compared to the general population and this could be a potential source of bias. However, age and income were not significant predictors of self-reported or curbside avoidable food wasting behavior (Tables 5 and 6). While counter-intuitive, household income has an equivocal impact on food waste generation (Graham-Rowe et al., 2014; Jorissen et al., 2015; Neff, 2015; Van Garde and Woodburn, 1987).

What clearly emerged in this study is the role of perceived behavioral control as the key TPB determinant of behavior. The linear regression analyses of both self-reported and curbside food waste revealed that perceived behavioral control was a stronger determinant of this behavior than intention, confirming Hypothesis 2. In fact, intention did not appear to assume any role in explaining this behavior. Perceived behavioral control is notably the only TPB determinant to be directly associated with this behavior.

It is possible that both self-reported and curbside avoidable food wasting could be better predicted if the positions of intention and perceived behavioral control (Fig. 1) were swapped. Perceived behavioral control may be a proxy for a survey respondent's assessment of their household's intention to not waste food or more pointedly their ability to infuse their intention into efficacious group behavior. Therefore, the progression of survey respondent intention to behavior is devolved to the fraction of respondent intention shared by the full household.

In contrast to self-reported behavior, other key determinants of curbside food waste are more extensively related to factors that potentially impact the amount of food that is purchased or put out to the curb. This includes the number of people/children in a household and the good provider identity, which mirror key perceived behavioral control determinants, as well as household planning habits and backyard composter usage. The strong influence of the good provider identity in this research may have in part been due to the high proportion of females that completed our survey. Graham-Rowe et al. (2014) notably reported on the conflict faced by parents, particularly mothers, who want to be a good food provider to their children even if that meant wasting some amount of that food. It suggests that possible underestimation of selfreported behavior obviates the impacts of these determinants.

\subsection{Implications}

The foregoing discussion exposes some of the limitations of using a survey to gather intention and avoidable food wasting frequency and quantity data. Survey respondents could be subject to response or survey bias and feel pressure to provide answers that are socially acceptable. It may be that the results of self-reported intention are exaggerated, while food wasting behaviors are downplayed. However, this has more to do with the implementation of 
the TPB, rather than the theory itself. While the only way to uncover people's intentions is by asking them, there is clearly more than one way to collect behavior data. Collecting curbside samples is one way to remove the vagaries of human memory, emotion, and possible observer bias used to self-report behavior. The results of this study suggest there are weaker relationships between TPB behavioral determinants and curbside data as compared to selfreported data. This lower predictive capacity may expose a limitation of the TPB. Quested et al. (2013, p. 48) noted that it is challenging to apply behavioral models, such as the TPB, to the wasting of food because it emanates from multiple behaviors rather than a single behavior. Curbside food wasting may reveal behaviors not captured in the survey, particularly the extent of these behaviors.

Notable is that perceived behavioral control appeared to have much greater and significant predictive capacity than intention and that this transcended both bivariate correlations and the linear regressions of both self-reported and curbside avoidable food wasting behavior. Intervention development should thus focus on strengthening perceived behavioral control and its significant determinants, in particular the good provider identity and subjective norms. Additional consideration should be given to larger households and households with children.

\section{Conclusions}

While there is some consensus between survey respondent selfreported versus curbside avoidable food wasting behavior, it is likely that survey respondents underestimated how much food they wasted. The collection of curbside food waste samples is an important way to more objectively measure food wasting behavior,

Table A1

Survey items per behavioral determinant, including mean, standard deviation, corrected item-total correlation ( $r$ pbis) per item, as well as internal reliability (Cronbach's $\alpha$ ).

\begin{tabular}{|c|c|c|c|c|c|c|}
\hline & M & SD & $\begin{array}{l}\text { Cronbach's } \\
\text { Alpha }\end{array}$ & M & SD & $\mathrm{r}_{\mathrm{pbis}}$ \\
\hline Intentions & 6.02 & 1.34 & 0.93 & & & \\
\hline I try to waste no food at all. & & & & 6.15 & 1.46 & 0.827 \\
\hline I always try to eat all purchased foods. & & & & 6.02 & 1.45 & 0.853 \\
\hline I try to produce only very little food waste. & & & & 5.97 & 1.45 & 0.874 \\
\hline I aim to use all leftovers. & & & & 5.94 & 1.53 & 0.813 \\
\hline \multicolumn{7}{|l|}{ Attitudes } \\
\hline Personal attitudes & 5.37 & 1.28 & 0.74 & & & \\
\hline It is unnecessary to waste food: it can always be used in some way. & & & & 5.17 & 1.65 & 0.603 \\
\hline It is immoral to discard foods while other people in the world are starving. & & & & 4.88 & 1.73 & 0.605 \\
\hline It upsets me when unused products end up in the waste bin or garburator. & & & & 6.05 & 1.31 & 0.505 \\
\hline Financial attitudes & 5.42 & 1.14 & 0.62 & & & \\
\hline I think that wasting food is a waste of money. & & & & 6.48 & 0.98 & 0.264 \\
\hline I cannot afford to pay for foods that are then discarded. & & & & 4.54 & 1.92 & 0.478 \\
\hline Saving money does not motivate me to discard less food. & & & & 5.14 & 1.83 & 0.366 \\
\hline I rarely think about money when I throw away food. & & & & 5.51 & 1.77 & 0.536 \\
\hline Environmental attitudes & 5.98 & 1.24 & 0.49 & & & \\
\hline Throwing out food does not have an environmental impact. & & & & 6.35 & 1.27 & 0.342 \\
\hline I rarely think about the environment when I throw away food. & & & & 5.62 & 1.75 & 0.342 \\
\hline Food safety attitudes & 2.75 & 1.18 & 0.60 & & & \\
\hline I believe that the risk of becoming ill as a result of eating food past its "best before" date is high. & & & & 3.44 & 1.79 & 0.383 \\
\hline I am not worried that eating leftovers results in health damage. & & & & 3.04 & 2.16 & 0.318 \\
\hline I think that consuming leftovers is harmless. & & & & 1.93 & 1.37 & 0.369 \\
\hline I think that one can perfectly safely eat food products whose "best before" dates expired a few days & & & & 2.57 & 1.60 & 0.519 \\
\hline Perceived Behavioral Control & 5.20 & 1.39 & 0.82 & & & \\
\hline I find it difficult to prepare a new meal from leftovers. & & & & 5.23 & 1.79 & 0.587 \\
\hline I find it difficult to make sure that only small amounts of food are discarded in my household. & & & & 4.99 & 1.81 & 0.681 \\
\hline I find it difficult to plan my food shopping in such a way that all the food I purchase is eaten. & & & & 4.88 & 1.98 & 0.691 \\
\hline I have the feeling that I cannot do anything about the food wasted in my household. & & & & 5.94 & 1.42 & 0.561 \\
\hline Other household members make it impossible for me to reduce the amount of food wasted in my household. & & & & 5.08 & 2.03 & 0.591 \\
\hline Subjective norms & 5.58 & 1.53 & 0.82 & & & \\
\hline People who are important to me find my attempts to reduce the amount of food wasted unnecessary. & & & & 5.30 & 1.81 & 0.709 \\
\hline People who are important to me disagree when I try to reduce my food waste. & & & & 5.86 & 1.49 & 0.709 \\
\hline Personal norms & 5.83 & 1.23 & 0.90 & & & \\
\hline I feel bad when I throw food away. & & & & 6.25 & 1.15 & 0.74 \\
\hline I feel obliged not to waste any food. & & & & 5.78 & 1.43 & 0.833 \\
\hline It is contrary to my principles when I have to discard food. & & & & 5.65 & 1.46 & 0.808 \\
\hline I have been raised to believe that food should not be wasted and I still live according to this principle. & & & & 5.62 & 1.51 & 0.769 \\
\hline Good provider identity & 3.64 & 1.23 & 0.64 & & & \\
\hline $\begin{array}{l}\text { It would be embarrassing to me if my guests ate all the food I had prepared for them. They would probably have } \\
\text { liked to eat more. }\end{array}$ & & & & 3.04 & 2.01 & 0.351 \\
\hline I regularly buy many fresh products although I know that not all of them will be eaten. & & & & 3.22 & 2.04 & 0.355 \\
\hline I like to provide a large variety of foods at shared mealtimes so that everyone can have something he or she likes. & & & & 3.90 & 1.89 & 0.444 \\
\hline I always have fresh products available to be prepared for unexpected guests or events (e.g. illness). & & & & 3.45 & 1.85 & 0.308 \\
\hline When I am expecting guests, I like to buy more food than is necessary because I am a generous host. & & & & 4.60 & 1.78 & 0.527 \\
\hline Household Planning Habits & 4.36 & 1.35 & 0.78 & & & \\
\hline When I have made a shopping list, I always keep strictly to it. & & & & 3.93 & 1.76 & 0.507 \\
\hline I am a person who likes to plan things. & & & & 5.24 & 1.63 & 0.552 \\
\hline $\begin{array}{l}\text { Before I prepare food, I always consider precisely how much I need to prepare and what I will do with the left } \\
\text { overs. }\end{array}$ & & & & 4.52 & 1.81 & 0.584 \\
\hline I always plan the meals in my household ahead and I keep to this plan. & & & & 3.75 & 1.77 & 0.703 \\
\hline
\end{tabular}


Table A2

Results of linear hierarchical regression analysis on intention to avoid food waste.

\begin{tabular}{llll}
\hline & B & SE & $\beta$ \\
\hline (Constant) & 18.03 & 3.37 & \\
Perceived health risks & -0.15 & 0.08 & -0.14 \\
Perceived behavioral control & 0.20 & 0.06 & $0.27^{* * *}$ \\
Personal norms & 0.20 & 0.08 & $0.18^{*}$ \\
$\mathrm{R} 2=0.19, \mathrm{~F}(3,178)=14.872, \mathrm{p}<0.001$ & & \\
\hline
\end{tabular}

${ }_{* *}^{*} \mathrm{p}<0.05$.

*** $\mathrm{p}<0.001$

and where possible, should supplement self-reported data. The relationships with TPB behavioral determinants, while similar, were weaker for curbside food wasting behavior. It is perceived behavioral control, rather than intention, that should be the pivot around which interventions are developed. Special attention should be given to non-TPB determinants relating to the potential quantity of food purchased, such as the good provider identify and household size. Future research should consider collecting survey and curbside waste samples at the same time, undertaking a follow up survey to see how behavioral determinants change over time, and identifying and adding other determinants to the TPB model that can potentially estimate (e.g., amount spent on groceries in a week) and/or predict (e.g., number of times groceries are purchased per week) the quantity of food purchased by a household that has the potential to become waste.

\section{Declaration of Competing Interest}

None.

\section{Acknowledgements}

The authors acknowledge Mr. Jay Stanford, Director, Environment, Fleet \& Solid Waste, City of London, Ontario, Canada with assistance in distributing this survey; and Mr. Martin Zivcak for research assistance.

This work was funded by Social Sciences and Humanities Research Council of Canada (Grant \#430-2017-01113).

\section{Appendix A}

See Tables A1 and A2.

\section{References}

Abdulla, M., Martin, R.C., Gooch, M., Jovel, E., 2013. The importance of quantifying food waste in Canada. J. Agric., Food Syst., Community Dev. 3 (2), 137-151.

Ajzen, I., 1991. The theory of planned behavior. Organ. Behav. Hum. Decis. Process. 50 (2), 179-211.

Ajzen, I., 2006a. Constructing a TPB Questionnaire. Retrieved from http://people. umass.edu/aizen/pdf/tpb.measurement.pdf.

Ajzen, I., 2006b. Sample TPB Questionnaire. Retrieved from http://people.umass. edu/aizen/pdf/tpb.questionnaire.pdf.

Ajzen, I., 2011. The theory of planned behaviour: Reactions and reflections. Psychology \& Health 26 (9), 1113-1127. https://doi.org/10.1080/ 08870446.2011.613995.

Ajzen, I., 2015. Consumer attitudes and behavior: the theory of planned behavior applied to food consumption decisions. Rivista di Economia Agraria 70 (2), 121 138.

Alexandratos, N., Bruinsma, J., 2012. World agriculture towards 2030/2050: the 2012 revision. ESA Working paper No. 12-03. Rome, FAO. Retrieved from www.fao.org/economic/esa.

ASTM, 2008. Standard test for determination of the composition of unprocessed municipal solid waste. In: ASTM D5231-92. American Society for Testing and Materials. US.

Barr, S., 2006. Environmental action in the home: Investigating the "value-action" gap. Geography 91, 43-54
Beretta, C., Stoessel, F., Baier, U., Hellweg, S., 2013. Quantifying food losses and the potential for reduction in Switzerland. Waste Manage. 33 (3), 764-773. https:// doi.org/10.1016/j.wasman.2012.11.007.

Buzby, J., Hyman, J., 2012. Total and per capita value of food loss in the United States. Food Policy 37 (5), 561-570. https://doi.org/10.1016/ j.foodpol.2012.06.002.

Cappellini, B., Parsons, E., 2012. Practising thrift at dinnertime: mealtime leftovers, sacrifice and family membership Practising thrift at dinnertime: mealtime leftovers, sacrifice and family membership. Sociological Rev. (Keele) 60 (suppl.2), 121-134. https://doi.org/10.1111/1467-954X.12041.

CEC, 2017. Characterization and Management of Food Loss and Waste in North America. Retrieved from Montreal, Canada: Commission for Environmental Cooperation.

Chung, S.-S., 2008. Using plastic bag waste to assess the reliability of self-reported waste disposal data. Waste Manage. 28 (12), 2574-2584.

Colton, T., 1974. Regression and Correlation. Little Brown and Company, Boston, USA.

Dhurandhar, N.V., Schoeller, D., Brown, A.W., Heymsfield, S.B., Thomas, D., Sørensen, T.I... .Group, E.B.M.W., 2015. Energy balance measurement: when something is not better than nothing. Int. J. Obesity 39 (7), 1109.

Evans, D., 2011. Blaming the consumer-once again: the social and material contexts of everyday food waste practices in some English households. Crit. Public Health 21 (4), 429-440.

Evans, D., 2012. Beyond the throwaway society: Ordinary domestic practice and a sociological approach to household food waste. Sociology (Oxford) 46 (1), 4156. https://doi.org/10.1177/0038038511416150.

Evans, D., 2014. Food Waste: Home Consumption. Material Culture and Everyday Life. Bloomsbury Academic, London.

Evans, D., Welch, D., Swaffield, J., 2017. Constructing and mobilizing 'the consumer': Responsibility, consumption and the politics of sustainability. Environ. Planning A 49 (6), 1396-1412. https://doi.org/10.1177/0308518X17694030.

FAO/Infoods, 2012. Density Databases, Version 2. Retrieved from Rome, Italy: http://www.fao.org/infoods/infoods/tables-and-databases/faoinfoodsdatabases/en/.

Folkes, V., Matta, S., 2004. The effect of package shape on consumers' judgments of product volume: attention as a mental contaminant. J. Consumer Res. 31 (2) 390-401.

Ganglbauer, E., Fitzpatrick, G., Comber, R., 2013. Negotiating food waste: Using a practice lens to inform design. ACM Trans. Comput.-Hum. Interact. (TOCHI) 20 (2), 11.

Graham-Rowe, E., Jessop, D.C., Sparks, P., 2014. Identifying motivations and barriers to minimising household food waste. Resour. Conserv. Recycl. 84, 15-23. https://doi.org/10.1016/j.resconrec.2013.12.005.

Graham-Rowe, E., Jessop, D.C., Sparks, P., 2015. Predicting household food waste reduction using an extended theory of planned behaviour. Resour. Conserv. Recycl. 101, 194-202. https://doi.org/10.1016/j.resconrec.2015.05.020.

Gustavsson, J., Cederberg, C., Sonesson, U., Van Otterdijk, R., Meybeck, A., 2011. Global food losses and food waste: extent, causes and prevention. Retrieved from Food and Agriculture Organization of the United Nations, Rome: http:// www.fao.org/docrep/014/mb060e/mb060e.pdf.

Handal, A.J., McGough-Maduena, A. Páez, M., Skipper, B., Rowland, A.S., Fenske, R. A Harlow, S.D., 2015. A pilot study comparing observational and questionnaire surrogate measures of pesticide exposure among residents impacted by the Ecuadorian flower industry. Arch. Environ. Occup. Health 70 (4), 232 240.

Hulin, B., 2011. The Keepsake Cookbook: Gathering Delicious Memories One Recipe at a Time. Lyons Press.

Jorissen, J., Priefer, C., Brautigam, K.-R., 2015. Food waste generation at household level: Results of a survey among employees of two European research centers in Italy and Germany. Sustainability (United States) 7 (3), 2695-2715. https://doi. org/10.3390/su7032695.

Kantor, L.S., Lipton, K., Manchester, A., Oliveira, V., 1997. Estimating and addressing America's food losses. Food Rev. 20 (1), 2-12.

Klee, A., Carruth, D., 1970. Sample weights in solid waste composition studies. J. Sanitary Eng. Div. 96 (4), 945-954.

Koivupuro, H.-K., Hartikainen, H., Silvennoinen, K., Katajajuuri, J.-M., Heikintalo, N. 2012. Influence of socio-demographical, behavioural and attitudinal factors on the amount of avoidable food waste generated in Finnish households Factors influencing household food waste. Int. J. Consumer Stud. 36 (2), 183-191. https://doi.org/10.1111/j.1470-6431.2011.01080.x.

Kormos, C., Gifford, R., 2014. The validity of self-report measures of proenvironmental behavior: A meta-analytic review. J. Environ. Psychology 40, 359-371.

Kreith, F., Tchobanoglous, G., 2002. Handbook of Solid Waste Management McGraw-Hill, New York; London.

Langley, J., Yoxall, A., Manson, G., Lewis, W., Waterhouse, A., Thelwall, D., Leech, B. 2009. The use of uncertainty analysis as a food waste estimation tool. Waste Manage. Res. 27 (3), 199-206. https://doi.org/10.1177/0734242X08095231.

Lebersorger, S., Schneider, F., 2011. Discussion on the methodology for determining food waste in household waste composition studies. Waste Manage. 31 (9-10), 1924-1933.

Lee, K.C.L., 2018. Grocery shopping, food waste, and the retail landscape of cities: The case of Seoul. J. Cleaner Prod. 172, 325-334. https://doi.org/10.1016/j. jclepro.2017.10.085

Maystre, L.Y., Viret, F., 1995. A goal-oriented characterization of urban waste. Waste Manage. Res. 13 (3), 207-218. https://doi.org/10.1177/0734242X9501300303. 
Melbye, E.L., Onozaka, Y., Hansen, H., 2016. Throwing it all away: Exploring affluent consumers' attitudes toward wasting edible food. J. Food Prod. Mark. 1-14. https://doi.org/10.1080/10454446.2015.1048017.

Neff, R.A., 2015. Wasted food: U.S. consumers' reported awareness, attitudes, and behaviors. PloS One 10 (6). https://doi.org/10.1371/journal.pone.0127881. e0127881.

Nellemann, C., MacDevette, M., Manders, T., Eickhout, B., Svihus, B., Prins, A., G., K., B. P. (Eds.), 2009. The environmental food crisis-The environment's role in averting future food crises. A UNEP rapid response assessment. Retrieved from www.grida.no.

Nunnally, J.C., Bernstein, I.H., 1978. Psychometric theory.

Parfitt, J., Barthel, M., MacNaughton, S., 2010. Food waste within food supply chains: Quantification and potential for change to 2050. Philos. Trans. Royal Soc. B: Biol. Sci. 365 (1554), 3065-3081. https://doi.org/10.1098/rstb.2010.0126.

Parizeau, K., von Massow, M., Martin, R., 2015. Household-level dynamics of food waste production and related beliefs, attitudes, and behaviours in Guelph, Ontario. Waste Manage. 35, 207-217. https://doi.org/10.1016/j.wasman. 2014.09.019.

Porpino, G., 2016. Household food waste behavior: Avenues for future research. J. Assoc. Consumer Res. 1 (1), 41-51. https://doi.org/10.1086/684528.

Prince, S.A., Adamo, K.B., Hamel, M.E., Hardt, J., Gorber, S.C., Tremblay, M., 2008. A comparison of direct versus self-report measures for assessing physical activity in adults: a systematic review. Int. J. Behavioral Nutr. Phys. Activity 5 (1), 56.

Quested, T.E., Marsh, E., Stunell, D., Parry, A.D., 2013. Spaghetti soup: The complex world of food waste behaviours. Resour. Conserv. Recycl. 79, 43-51. https://doi. org/10.1016/j.resconrec.2013.04.011.

Ramstedt, M., 2010. How much alcohol do you buy? A comparison of self-reported alcohol purchases with actual sales. Addiction 105 (4), 649-654.

Romani, S., Grappi, S., Bagozzi, R.P., Barone, A.M., 2018. Domestic food practices: A study of food management behaviors and the role of food preparation planning in reducing waste. Appetite 121, 215-227.

Rugg, F.M., 1997. Solid waste, characterization methods. In: Liu, D.H.F., Lipták, B.I.G. (Eds.), Environmental Engineers' Handbook. second ed. CRC Press LLC, Boca Raton, Fla, pp. 1158-1174.

Russell, S.V., Young, C.W., Unsworth, K.L., Robinson, C., 2017. Bringing habits and emotions into food waste behaviour. Resour. Conserv. Recycl. 125, 107-114.

Schanes, K., Dobernig, K., Gözet, B., 2018. Food waste matters-A systematic review of household food waste practices and their policy implications. J. Cleaner Prod. 182, 978-991.

Seebauer, S., Fleiß, J., Schweighart, M., 2017. A household is not a person: Consistency of pro-environmental behavior in adult couples and the accuracy of proxy-reports. Environ. Behav. 49 (6), 603-637.

Sharma, M., McBean, E., 2007. A methodology for solid waste characterization based on diminishing marginal returns. Waste Manage. 27 (3), 337-344. https://doi. org/10.1016/j.wasman.2006.02.007.

Silvennoinen, K., Katajajuuri, J.M., Hartikainen, H., Heikkila, L., Reinikainen, A., 2014 Food waste volume and composition in Finnish households. Br. Food J. 116 (6) 1058-1068. https://doi.org/10.1108/bfj-12-2012-0311.

Stancu, V., Haugaard, P., Lahteenmaki, L., 2016. Determinants of consumer food waste behaviour: Two routes to food waste. Appetite 96, 7-17. https://doi.org/ 10.1016/j.appet.2015.08.025.
Statistics Canada, 2016. Census Profile, 2016 Census, London [Census metropolitan area], Ontario and Ontario [Province]. Retrieved from http://www12.statcan.gc. ca/census-recensement/2016/dp-pd/prof/details/page.cfm?Lang=E\&Geo1= CMACA\&Code $1=555 \&$ Geo2 $=$ PR\&Code2 $=35 \&$ Data $=$ Count\&SearchText=london $\&$ SearchType=Begins\&SearchPR=01\&B1=All\&TABID $=1$.

Stefan, V., van Herpen, E., Tudoran, A.A., Lähteenmäki, L., 2013. Avoiding food waste by Romanian consumers: The importance of planning and shopping routines. Food Qual. Prefer. 28 (1), 375-381. https://doi.org/10.1016/j.foodqual. 2012.11.001.

Tike, 2010. Balance Sheet for Food Commodities 2008 and 2009. Retrieved from http://www.maataloustilastot.fi/sites/default/files/ravintotase_2009_ennakko. pdf.

Valigursky, M.L., 2011. A pinch, a smidge, a dollop and a handful - measurement conversions.

van der Werf, P., Gilliland, J.A., 2017. A systematic review of food losses and food waste generation in developed countries. Proc. Inst. Civil Eng.-Waste Resour. Manage., 1-12

van der Werf, P., Seabrook, J.A., Gilliland, J.A., 2019. Food for naught: Using the theory of planned behaviour to better understand household food wasting behaviour. The Canadian Geographer/Le Géographe canadien 63 (2), 1-16. https://doi.org/10.1111/cag.12519.

Van Garde, S.J., Woodburn, M.J., 1987. Food discard practices of householders. J. Am. Diet. Assoc. 87 (3), 322-329.

van Herpen, E., van der Lans, I., I., N.-d.V., Holthuysen, N., Kremer, S., Stijnen, D., 2016. Consumption life cycle contributions - Assessment of practical methodologies for in-home waste measurement. Retrieved from Wageningen University: www.eu-refresh.org.

Viinisalo, M., Nikkilä, M., Varjonen, J., 2008. Elintarvikkeiden kulutusmuutokset kotitalouksissa vuosina 1966-2006. Abstract: Changes in the Consumption of Foods in Households during the Years 1966-2006. Retrieved from https://helda. helsinki.fi/bitstream/handle/10138/152387/Elintarvikkeiden_ kulutusmuutokset_kotitalouksissa_vuosina_1966-2006.pdf? sequence=1.

Visschers, V., Wickli, N., Siegrist, M., 2016. Sorting out food waste behaviour: A survey on the motivators and barriers of self-reported amounts of food waste in households. J. Environ. Psychology 45, 66-78. https://doi.org/10.1016/ j.jenvp.2015.11.007.

Whybrow, S., Stubbs, R., Johnstone, A., O'reilly, L., Fuller, Z., Livingstone, M., Horgan, G., 2016. Plausible self-reported dietary intakes in a residential facility are not necessarily reliable. Eur. J. Clin. Nutr. 70 (1), 130.

WRAP, 2007. Food behaviour consumer research: quantitative phase. Retrieved from http://www.wrap.org.uk/sites/files/wrap/Food\%20behaviour\% 20consumer\%20research\%20quantitative\%20jun\%202007.pdf.

WRAP, 2009. Household food and drink waste in the UK. Retrieved from Banbury UK. http://www.wrap.org.uk/sites/files/wrap/Household_food_and_drink_ waste_in_the_UK_-_report.pdf.

WRAP, 2013. Estimates of waste in the food and drink supply chain. Retrieved from WRAP, Banbury UK: http://www.wrap.org.uk/sites/files/wrap/Estimates\%20of\% 20waste\%20in\%20the\%20food\%20and\%20drink\%20supply\%20chain_0.pdf.

Yu, C.-C., Maclaren, V., 1995. A comparison of two waste stream quantification and characterization methodologies. Waste Manage. Res. 13 (4), 343-361. 